\title{
Platelet Munc13-4 regulates hemostasis, thrombosis and airway inflammation
}

\author{
Eduardo I. Cardenas,,$^{1,2}$ Keegan Breaux, ${ }^{1}$ Qi Da, ${ }^{3,4}$ Jose R. Flores, ${ }^{1}$ \\ Marco A. Ramos, ${ }^{1}$ Michael J. Tuvim, ${ }^{1}$ Alan R. Burns, ${ }^{5}$ Rolando E. Rumbaut ${ }^{3,4}$ \\ and Roberto Adachi ${ }^{1}$
}

${ }^{1}$ Department of Pulmonary Medicine, The University of Texas MD Anderson Cancer Center, Houston, TX, USA; ${ }^{2}$ Tecnologico de Monterrey, Escuela de Ingenieria y Ciencias, Monterrey, Mexico; ${ }^{3}$ Center for Translational Research on Inflammatory Diseases (CTRID), Michael E. DeBakey Veterans Affairs Medical Center, Houston, TX, USA; ${ }^{4}$ Department of Medicine, Baylor College of Medicine, Houston, TX, USA and ${ }^{5}$ College of Optometry, University of Houston, TX, USA

\section{ABSTRACT}

$\mathrm{P}$ latelet degranulation is crucial for hemostasis and may participate in inflammation. Exocytosis in platelets is mediated by SNARE proteins and should be controlled by Munc13 proteins. We found that platelets express Munc13-2 and -4. We assessed platelet granule exocytosis in Munc13-2 and -4 global and conditional knockout (KO) mice, and observed that deletion of Munc13-4 ablates dense granule release and indirectly impairs alpha granule exocytosis. We found no exocytic role for Munc13-2 in platelets, not even in the absence of Munc13-4. In vitro, Munc13-4-deficient platelets exhibited defective aggregation at low doses of collagen. In a flow chamber assay, we observed that Munc13-4 acted as a rate-limiting factor in the formation of thrombi. In vivo, we observed a dose-dependency between Munc13-4 expression in platelets and both venous bleeding time and time to arterial thrombosis. Finally, in a model of allergic airway inflammation, we found that platelet-specific Munc13-4 KO mice had a reduction in airway hyper-responsiveness and eosinophilic inflammation. Taken together, our results indicate that Munc13-4-dependent platelet dense granule release plays essential roles in hemostasis, thrombosis and allergic inflammation.

\section{Introduction}

A key effector response from platelets is exocytosis of their alpha, dense and lysosomal granules. Alpha granules are the most abundant, and contain soluble molecules and receptors that propagate platelet activation and aggregation. ${ }^{1}$ Dense granules are secreted at a faster rate and store ADP, an autocrine agonist for platelet activation. ${ }^{2}$ Lysosomal granules contain membrane-associated proteins and acidhydrolases, and may contribute to thrombus remodeling. ${ }^{3}$

During exocytosis, the membrane of a platelet granule fuses with the plasma membrane. This requires the formation of a SNARE (soluble N-ethylmaleimidesensitive factor attachment protein receptor) complex by proteins localized on both membranes. ${ }^{4}$ Prior to fusion, granules are brought close to the plasma membrane by tethering and docking processes, but this proximity is not sufficient to drive fusion, it also requires priming. ${ }^{5}$ Fundamental to priming is the interaction of Munc (mammalian homolog of C. elegans uncoordinated gene) 13 with Munc18, which allows Syntaxin to interact with the other exocytic SNARE proteins. ${ }^{6}$ Among the four paralogs of Munc13, only Munc13-4 has been studied in mouse platelets. ${ }^{7}$ Different groups have agreed that deletion of Munc13-4 inhibits primarily dense granule release, ${ }^{8,9}$ which may affect alpha granule exocytosis ${ }^{9,10}$ or integrin $\alpha_{\mathrm{IL}} \beta_{3}$ activation ${ }^{11}$ depending on experimental variables. ${ }^{12}$ In addition, global deficiency of Munc13-4 affects hemostasis, probably due to defective platelet exocytosis, ${ }^{10,11,13}$ a difficult conclusion to reach because Munc13-4 is also expressed in other tissues important for hemostasis (e.g. endothelial cells). ${ }^{14}$ In humans, mutations in the gene encoding Munc13-4 cause familial hemophagocytic lymphohistiocytosis type 3 (FHL3), an autosomal recessive disorder characterized by defective secretion in cytotoxic T lymphocytes and natural killer cells, multisystemic inflam-
Haematologica 2018

Volume 103(7):1235-1244

\section{Correspondence:}

radachi@mdanderson.org

Received: November 30, 2017.

Accepted: April 12, 2018.

Pre-published: April 19, 2018.

doi:10.3324/haematol.2017.185637

Check the online version for the most updated information on this article, online supplements, and information on authorship \& disclosures: www.haematologica.org/content/103/7/xxx

\section{(C)2018 Ferrata Storti Foundation}

Material published in Haematologica is covered by copyright. All rights are reserved to the Ferrata Storti Foundation. Use of published material is allowed under the following terms and conditions:

https://creativecommons.org/licenses/by-nc/4.0/legalcode. Copies of published material are allowed for personal or internal use. Sharing published material for non-commercial purposes is subject to the following conditions:

https://creativecommons.org/licenses/by-nc/4.0/legalcode, sect. 3. Reproducing and sharing published material for commercial purposes is not allowed without permission in writing from the publisher. 
mation, and organ infiltration by $\mathrm{CD}^{+} \mathrm{T}$ cells and macrophages. ${ }^{15}$ Platelets from FHL3 patients present defective degranulation, ${ }^{16}$ and bleeding diathesis has been reported in some patients with FHL3. ${ }^{17}$

There is mounting evidence that platelets participate in inflammation, including allergic airway disease. ${ }^{18}$ Patients with asthma have lower platelet counts ${ }^{19}$ and increased levels of markers of platelet activation ${ }^{20}$ after allergen exposure. Platelets have been found extravascularly in the airways, ${ }^{21}$ and platelet products have been measured in bronchoalveolar lavage (BAL) fluid of asthmatic patients. ${ }^{22}$ This suggests that platelets migrate to the lungs during asthma, which has been experimentally confirmed in mice. ${ }^{23}$ In animal models of asthma, platelet depletion has been shown to decrease the number of leukocytes infiltrating the airways ${ }^{24}$ and bronchoconstriction induced by allergen. ${ }^{25}$ Serotonin and/or ADP released from platelet dense granules may be responsible for these findings. In a mouse model of asthma, deletion of the enzyme that synthesizes serotonin in peripheral tissues caused a significant reduction in asthmatic symptoms. ${ }^{26}$ Multiple studies in mouse models of asthma have targeted the ADP receptor P2Y ${ }_{12}$ with mostly favorable outcomes, ${ }^{27,28}$ but there is evidence that the pro-inflammatory effects of platelets may be mediated by $\mathrm{P}_{2} \mathrm{Y}_{1}$ (another ADP receptor) and $\mathrm{P}_{2} \mathrm{Y}_{14}$ (a UDP-glucose receptor), and not $\mathrm{P} 2 \mathrm{Y}_{12}{ }^{29,30}$

Given that platelets participate in highly distinct physiological responses (hemostasis and airway inflammation), we investigated whether exocytosis of dense granules, so crucial for hemostasis, is also important for the development of asthma. We manipulated the expression of Munc13-2 and -4 in platelets in vivo. While absence of Munc13-2 had no significant effect, absence or reduced levels of Munc13-4 altered platelet dense granule secretion directly and alpha granule exocytosis indirectly, impairing platelet aggregation and thrombus formation. By using platelet-specific knockout (KO) mice, we proved that Munc13-4 from platelets, and not from other tissues, is required for venous and arterial hemostasis, and for arterial thrombosis in vivo. Finally, we observed that Munc13-4dependent platelet exocytosis is essential for the full development of allergic airway inflammation.

\section{Methods}

A detailed description of the blood collection and platelet isolation, expression studies, secretion and activation assays, electron microscopy and stereology, aggregometry and flow-chamber assays, in vivo thrombosis model, and statistical analysis is provided in the Online Supplementary Methods.

\section{Mice}

Munc13-2 $\mathrm{KO}$ and Munc13-4 global and conditional $\mathrm{KO}$ mice have been described previously. ${ }^{31,32}$ In short, we flanked exon 3 of the mouse Munc13-4 gene (Unc13d) with two loxP sites ("floxed" or $\mathrm{F}$ allele). Due to this genetic manipulation, mice homozygous for the $\mathrm{F}$ allele (Munc13-4 ${ }^{\mathrm{F} F}$ ) had a reduced expression of Munc13-4 globally (i.e. Munc13-4 ${ }^{\mathrm{FF}}$ mice are hypomorphs). Exon 3 contains the start codon of $U n c 13 d$, its sequence is present in all described splice variants of mouse Munc13-4, and its removal by Cre-mediated recombination eliminates Munc13-4 expression. ${ }^{32}$ We crossed Munc13-4 ${ }^{\mathrm{F} / \mathrm{F}}$ mice with B6.C-Tg(CMV-cre) $1 \mathrm{Cgn} / \mathrm{J}$ mice (The Jackson Laboratory \#006054), which express Cre recombinase ubiquitously, to delete $U n c 13 d$ in the germ line ${ }^{33}$ and generate our Munc13-4 global KO line (Munc13-4 ${ }^{-/}$). This line was propagated by heterozygote (Munc13-4 $4^{+/-}$) crossings to generate Munc13-4 $4^{-/-}$, Munc13-4 $4^{+/-}$and control Munc13-4 ${ }^{+/+}$littermates. We also generated megakaryocyte/platelet-specific $\mathrm{KO}$ mice (Munc13-4 $4^{\Delta / \Delta}$ ) by crossing Munc13-4 ${ }^{\mathrm{F} / \mathrm{F}}$ mice with C57BL/6$\mathrm{Tg}$ (Pf4-icre)Q3Rsko/J mice (Munc13-4 ${ }^{+++} \mathrm{Cre}^{+}$; The Jackson Laboratory \#008535), which selectively express Cre recombinase in megakaryocytes. Munc13-4 ${ }^{+/+} \mathrm{Cre}^{+}$mice were also used as additional controls.

All lines were on a C57BL/6J background, as confirmed by speed-congenics scanning for 105 SNPs. Mice of both sexes were used in all experiments. Mice were kept in a pathogen-free facility and handled in accordance with the Institutional Animal Care and Use Committees of the University of Texas MD Anderson Cancer Center and Baylor College of Medicine.

\section{Bleeding time tests}

We used mice $(20 \pm 2$ weeks old) of the same weight $(30 \pm 3 \mathrm{~g})$ anesthetized with Avertin (tribromoethanol in tert-amyl alcohol) $0.4 \mathrm{mg} / \mathrm{g}$ intraperitoneally (i.p.). In the transection model, tails were cut $5 \mathrm{~mm}$ from the tip with a razor blade, and bleeding depended mainly on the tail artery. For the incision model, we created a device to make a reproducible transversal dorsal tail incision $0.8 \mathrm{~mm}$ in depth at a point where the tail has a diameter of $3.8 \mathrm{~mm}$ (Online Supplementary Figure S1), sectioning only the dorsal tail venous plexus. In both models, the tails were immediately immersed in $37^{\circ} \mathrm{C}$ saline and the time to cessation of bleeding was recorded. All animals were euthanized after bleeding stopped or at 20 minutes (min).

\section{Asthma model}

Mice $(9 \pm 1$ weeks old) were sensitized i.p. on days 0 and 7 with $10 \mu \mathrm{g}$ ovalbumin (OVA; grade V) adsorbed to $1 \mathrm{mg}$ of aluminum potassium sulfate dodecahydrate (both from Sigma-Aldrich) in $100 \mu \mathrm{L}$ of saline. They were challenged once a day on days 19-21 in a nebulization chamber with 1\% OVA in PBS for 30 min using an Aerotech II jet nebulizer (Biodex) at $10 \mathrm{~L} / \mathrm{min}$. Then, they were studied on day 22. A detailed description of the airway mechanics assessment, airway mucin quantification, histology and BALs is provided in the Online Supplementary Methods.

\section{Results}

\section{Expression and targeting of Munc13 proteins in platelets}

By $\mathrm{qPCR}$, we found that C57BL/6J platelets express Munc13-1, -2 and -4 (Figure 1A). We had created Munc13-4 global and conditional $\mathrm{KO}$ lines, ${ }^{32}$ and we obtained Munc13-2 KO mice (Dr. Christian Rosenmund, Charité Universitaetsmedizin). ${ }^{31}$ We did not study Munc13-1 because its global deletion is perinatally lethal ${ }^{34}$ and a conditional $\mathrm{KO}$ line was not available. We confirmed lack of Munc13-2 and normal expression levels of Munc13-1 and -4 in Munc13-2 $2^{-/-}$platelets (Figure 1B). Immunoblots of tissues and platelets from all Munc13-4 mutants confirmed the global reduction and absence of Munc13-4 expression in Munc13-4 ${ }^{+/-}$and Munc13-4 $4^{-/-}$, respectively, and the specific deletion of Munc13-4 in platelets in Munc13-4 $4^{\Delta \Delta}$ mice (Figure 1C). The decreased expression in Munc13-4 $4^{\mathrm{F} / \mathrm{F}}$ mice to approximately $20 \%$ has been reported, ${ }^{32}$ and we used it to interrogate dose-response relationships between Munc13-4 expression $(0,20,50,100 \%)$ and the outcomes of our experiments. 
A

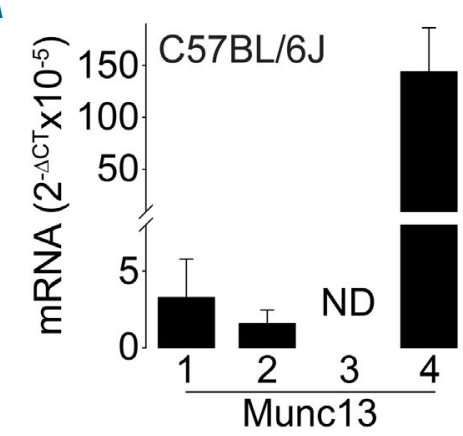

B

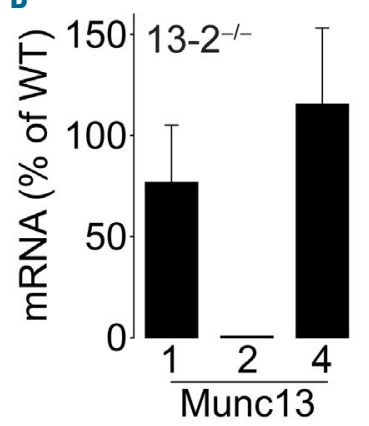

C

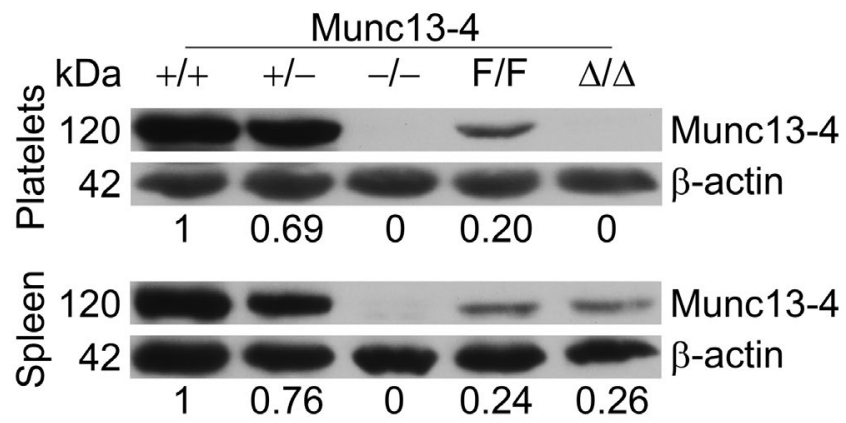

Figure 1. Munc13 expression and deletion. (A) RT-qPCR of all Munc13 proteins relative to $\beta$-actin in $\mathrm{C} 57 \mathrm{BL} / 6 \mathrm{~J}$ platelets. $\mathrm{N}=3$. (B) RT-qPCR from Munc13-2 $2^{-/}$platelets. All values are relative to $\beta$-actin and Munc13 isoform levels in Munc13-2 $2^{+/+}$platelets (WT). $\mathrm{N}=3$. Bar: mean; error bar: Standard Error of Mean. (C) Representative immunoblots of platelet and spleen lysates from all Munc13-4 mutant mice probed with anti-mouse Munc13-4 antibody. $\beta$-actin was used as loading control. Numbers below blots represent densitometry results relative to $\beta$-actin and Munc13-4 $4^{+/+}$. ND: not detected.

\section{Munc13-4 regulates platelet dense granule exocytosis}

To test how different Munc13 isoforms contribute to platelet granule secretion, we assessed exocytosis of each type of platelet granule. We measured the translocation of $P$-selectin (alpha granules) and LAMP-1 (lysosomal granules) to the plasma membrane, and the release of ATP (dense granules). To interrogate potential agonist-dependent differences, we activated platelets with collagen (Figure 2) and thrombin (Figure 3). Based on dose-response curves (Online Supplementary Figure S2), we chose a high and a low dose for each agonist. In agreement with previous reports, the concentration of collagen necessary to induce translocation of membrane-associated proteins ( $P$-selectin and LAMP-1) was higher than that required to induce release of soluble mediators (ATP).${ }^{35}$ There were no differences among all the wild-type (WT) controls from our Munc13-2, Munc13-4 and double KO (DKO) colonies, therefore we pooled them in a single control group (WT in Figures 2 and 3 ).

We observed that dense granule exocytosis was completely abolished in platelets lacking Munc13-4 regardless of the agonist used (Figures $2 \mathrm{~A}$ and $\mathrm{B}$, and $\mathrm{BA}$ and $\mathrm{B}$ ). With collagen, we documented a clear correlation between the level of expression of Munc13-4 (nil in $\Delta / \Delta,-/-$ and $\mathrm{DKO}$, approx. $20 \%$ in F/F, approx. $50 \%$ in $+/-$, and $100 \%$ in WT) and the secretion of ATP (Figure 2B). Although we observed a significant decrease in $P$-selectin translocation only at the lower dose of thrombin (Figures 2C and D, and $3 \mathrm{C}$ and D), we found a complete thrombin dependent defect in lysosomal granule exocytosis in platelets lacking Munc13-4 (Figures 2E and F, and $3 \mathrm{E}$ and F). Munc13-2-1platelets showed no defects in any of these tests. To assess if the consequences of removing Munc13-2 would manifest only in the absence of Munc13-4, we tested platelets from $\mathrm{DKO}$ mice and did not observe any additional exocytic defects (Figures 2 and 3).
Given the secondary effect of Munc13-4 on alpha granule release, ${ }^{9,10}$ we decided to further interrogate alpha granule exocytosis by measuring the release of platelet factor 4 (PF4). Interestingly, Munc13-4 $4^{-/-}$platelets had a significant reduction in PF4 release when stimulated with thrombin (Figure 3G). To test if the defects observed in alpha and lysosomal granule exocytosis could be indirectly caused by an impaired release of ADP from dense granules, we added exogenous ADP to stimulated platelets and showed that it was capable of rescuing PF4 release (Figure $3 \mathrm{G}$ ) and $P$-selectin translocation (Figure $3 \mathrm{H}$ ), but not LAMP-1 translocation (Figure 3I). Once again, Munc13-2 $2^{-/-}$platelets had no exocytic defect and DKO platelets failed to show any additional phenotype (Figure $3 \mathrm{G}$ ); we therefore decided to drop these two lines from subsequent experiments.

\section{Platelet granule biogenesis and platelet activation are Munc13-4-independent}

The exocytic defects observed in platelets lacking Munc13-4 could be due to defective platelet granule biogenesis. Therefore, we analyzed resting platelets by electron microscopy (EM) (Figure 4A). Stereological analysis of platelet profiles before stimulation revealed no difference in the volume densities $(\mathrm{Vv})$ of alpha or dense granules among all genotypes (Figure 4B and C). EM also provided an additional method to assess platelet exocytosis. After stimulation, $V_{V}$ of alpha and dense granules in Munc13-4 $4^{+/+}$platelets decreased due to loss of granules through exocytosis. However, Munc13-4-deficient (Munc13-4- $4^{-/}$and Munc13-4 ${ }^{\Delta / \Delta}$ ) platelets lost no dense granules (Figure 4C) and only a fraction of alpha granules (Figure 4B). Munc13-4 $4^{\mathrm{F} / \mathrm{F}}$ platelets showed an intermediate phenotype. To rule out the possibility that lack of Munc13-4 might interfere with inside-out platelet activation, we measured integrin $\alpha_{\mathrm{IIb}} \beta_{3}$ activation, and found no differences (Figure 4D). 


\section{Munc13-4-regulates platelet aggregation and thrombus stability}

To determine how the observed exocytic defects affect platelet function, we first studied platelet aggregation. When using a low concentration of collagen, platelets not expressing Munc13-4 did not undergo shape change (as evidenced by the flat aggregometry recordings) and were unable to form aggregates (Figure 5A and B). While hypomorphic Munc13-4 $4^{\mathrm{F} / \mathrm{A}}$ platelets underwent some shape change, they were still unable to form aggregates. Platelets from all genotypes underwent shape change and formed aggregates at similar levels when using a high dose of collagen (Figure $5 \mathrm{~A}$ and $\mathrm{B}$ ).

We then assessed platelet thrombus formation under shear stress in a collagen-coated flow chamber and documented a severe defect in Munc13-4-deficient platelets (Figure 5C). The severity of this defect increased at a higher shear stress (Figure 5D), which suggests that platelets lacking Munc13-4 are unable to form stable thrombi. At high shear, platelets with approximately $50 \%$ expression of Munc13-4 (Munc13-4+-) behaved normally, but those with approximately 20\% expression (Munc13-4/F) showed an intermediate defect.

In all our in vitro studies (Figures 2-5) platelets from Munc13-4 $4^{\Delta \Delta}$ mice behaved almost identically to those from Munc13-4 ${ }^{-/}$mice, eliminating inefficient Cre recom- bination as an explanation for the findings in the following in vivo studies.

\section{Lack of Munc13-4 disrupts hemostasis and thrombosis}

We used two tail-bleeding tests to study hemostasis. In the classical transection model, Munc13-4 deletant mice were unable to stop bleeding and were euthanized after $20 \mathrm{~min}$ (Figure 6A). Furthermore, the hypomorphic Munc13-4 $4^{\mathrm{FF}}$ mice displayed an identical bleeding diathesis. Because we did not observe a defect in thrombus formation ex vivo at low shear stress, we hypothesized that the Munc13-4 $4^{\mathrm{FF}}$ mice would stop bleeding if we avoided sectioning the tail ventral artery and induced only venous bleeding. With this in mind, we developed a device to make a reproducible incision on the tail dorsal venous plexus only (Online Supplementary Figure S1). Munc13-4-1 and Munc13-4 $4^{\Delta \Delta}$ mice still showed prolonged bleeding, but Munc13-4 ${ }^{\mathrm{FF}}$ mice behaved similarly to their WT counterparts (Figure 6B). This phenotype was not due to an abnormal number of platelets in the mutant mice (Table 1).

Finally, we assessed thrombosis in vivo with the $\mathrm{FeCl}_{3}$ model of carotid thrombosis. In accordance with our in vitro results, we did not observe vessel occlusion in Munc13-4 $4^{\Delta \Delta}$ mice, while WT arteries occluded in less than 5 min, and hypomorphic Munc13-4 $4^{\mathrm{F} / \mathrm{F}}$ mice presented an
A

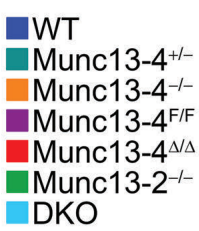

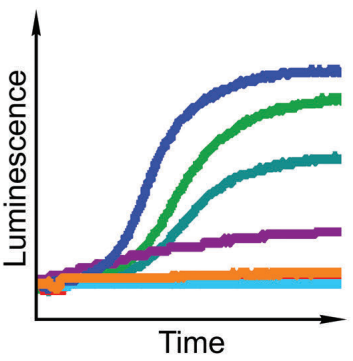

C

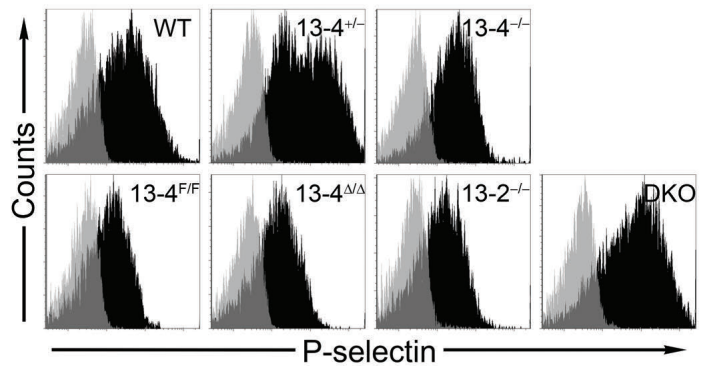

E

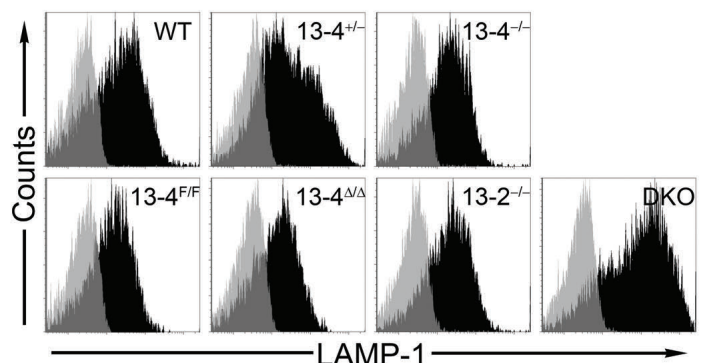

B

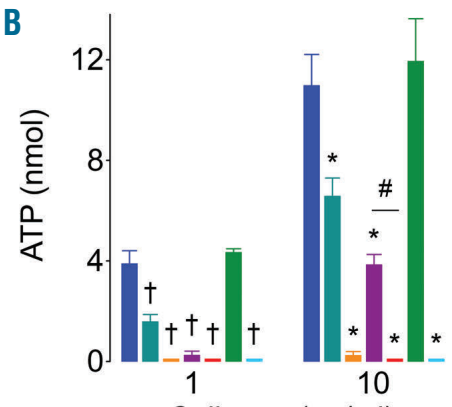

D

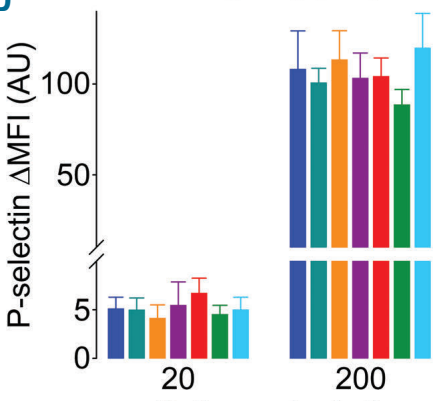

$\mathrm{F}$

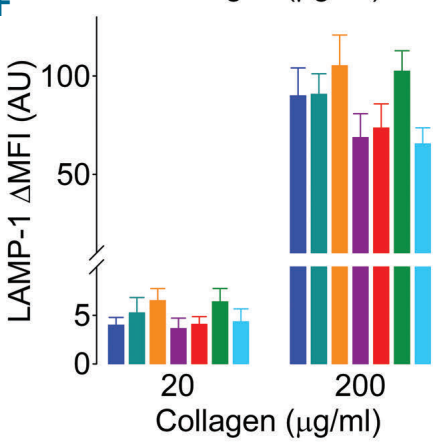

Figure 2. Deletion of Munc13-4 impairs dense granule release in collagen-stimulated platelets. Samples from wild-type mice for Munc13-2 and -4 (WT), Munc13-4 $+/-,-/-$, F/F, $\Delta / \Delta$, Munc13-2 $-/-$, and Munc13-2 and 4 double KO (DKO) mice were stimulated with collagen. Representative tracings (A) and mean release of ATP (dense granules) (B) measured by luminometry in whole blood. $\mathrm{N}=5-14$. Representative tracings $(\mathrm{C}$ and $\mathrm{E})$ and mean fluorescence intensity over baseline $(\triangle \mathrm{MFI})$ (D and F) of $P$-selectin (alpha granules) (C and D) and LAMP-1 (lysosomal granules) (E and F) translocated to the surface of washed platelets measured by flow cytometry. $\mathrm{N}=8-16$. Color legend in (A) applies to all panels. Bar: mean; error bar: Standard Error of Mean. ${ }^{\#} P<0.05 ;{ }^{\dagger} P<0.01$; $\star P<0.001$; comparisons are with WT unless otherwise specified. 
intermediate phenotype (Figure 6C). The proportion of vessels occluded at 30 min was $100 \%$ for Munc13-4 $4^{+/+}$ mice, $50 \%$ for Munc13-4 $4^{\mathrm{F} / \mathrm{F}}$ mice and $0 \%$ for Munc13-4 ${ }^{\mathrm{\Delta} \Delta}$ mice.

\section{Platelets contribute to allergic airway inflammation in a Munc13-4-dependent manner}

We observed that Munc13-4 $4^{-/}$mice were partially protected from developing AHR in a model of asthma. While looking for the cell responsible, we found that megakaryocyte/platelet-specific Munc13-4 KO mice presented a similar phenotype. We then studied our Munc13-4 mutant mice under an OVA-dependent acute model of allergic asthma. As expected, all OVA-exposed animals had an elevated baseline Rrs (total respiratory system resistance) compared to the naive controls (data not shown), and these baseline values were used to normalize the dose-response curves (Figure 7A). Given that the results in mice expressing Cre recombinase in their platelets (Munc13- $4^{+++} \mathrm{Cre}^{+}$ mice) were indistinguishable from those of Munc13-4+/ mice, we concluded that this effect was not a Cre-induced artifact. We found that, although there was no difference between Munc13-4 $4^{+/+}$and Munc13-4 $4^{\mathrm{F} / \mathrm{F}}$ mice, Munc13-4 ${ }^{\Delta / \Delta}$ mice completely mimicked the blunted AHR observed in Munc13-4 $4^{-/}$mice (Figure 7A and B). Analysis of methacholine PC1000 (data not shown) confirmed the same differences.

The protection observed in Munc13-4/- and Munc13-4 $4^{\Delta \Delta}$ mice was not related to changes in airway mucous metaplasia, as we observed no significant differences of intracellular epithelial mucin content in periodic acid-fluorescent Schiff (PAFS)-stained sections (Figure 7C
A

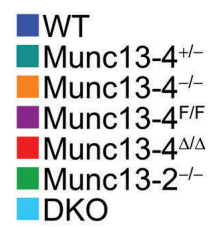

WT

Munc13-4-1-

Munc13-4 F/F

Munc13-4

DKO
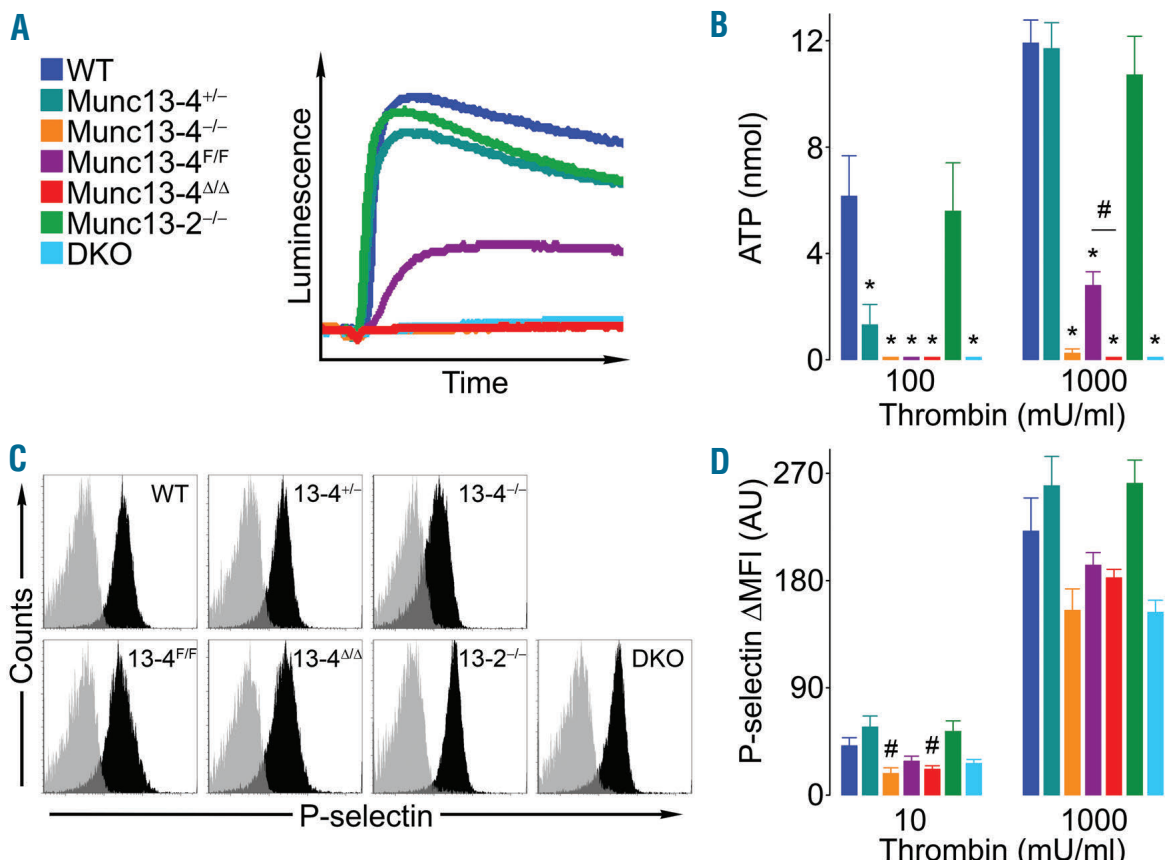
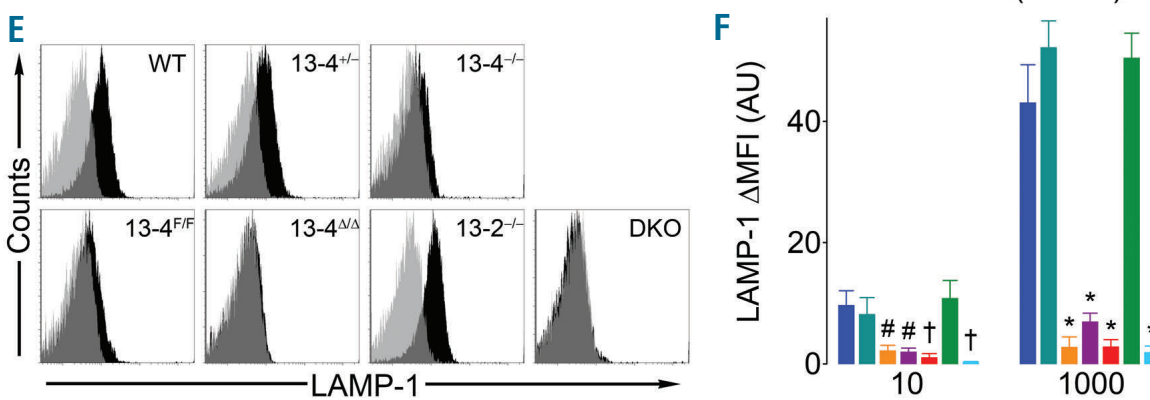

1000

Thrombin $(\mathrm{mU} / \mathrm{ml})$
G

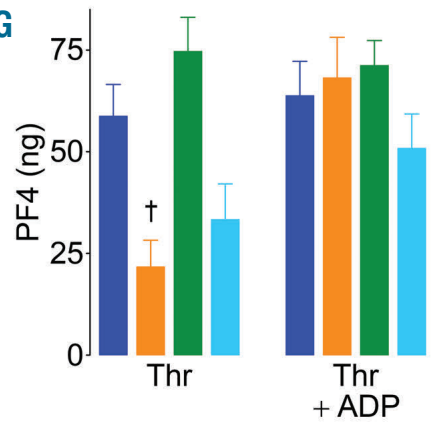

H

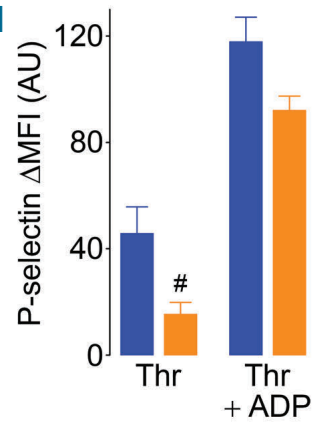

Figure 3. Deletion of Munc13-4 impairs dense and Iysosomal granule release directly and alpha granule release indirectly in thrombin-stimulated platelets. Samples from wild-type mice for Munc-13-2 and -4 (WT), Munc13-4 +/$-/-, \quad F / F, \Delta / \Delta$, Munc13-2 -/-, and Munc13-2 and -4 double knockout (DKO) mice were with thrombin (Thr) or thrombin and ADP $(10 \mu \mathrm{M})$. Representative tracings (A) and mean release of ATP (dense granules) (B) measured by luminometry in whole blood. $\mathrm{N}=5-9$. Representative trac ings ( $C$ and $E$ ) and mean fluorescence intensity over baseline $(\triangle M F I)(D, F, H$ and I) of $P$-selectin (alpha granules) (C, D and $\mathrm{H}$ ) and LAMP-1 (lysosomal granules) (E, F and I) translocated to the surface of washed platelets measured by flow cytometry. $\mathrm{N}=8-11$ (C-F), $\mathrm{N}=3$ ( $\mathrm{H}$ and I). (G) Mean release of PF4 (alpha granules) measured by ELISA. $\mathrm{N}=3-9$. Color legend in (A) applies to all panels. Bar: mean; error bar: Standard Error of Mean. ${ }^{\#} P<0.05$; ${ }^{\dagger} P<0.01$; $* P<0.001$; comparisons are with WT unless otherwise specified. 

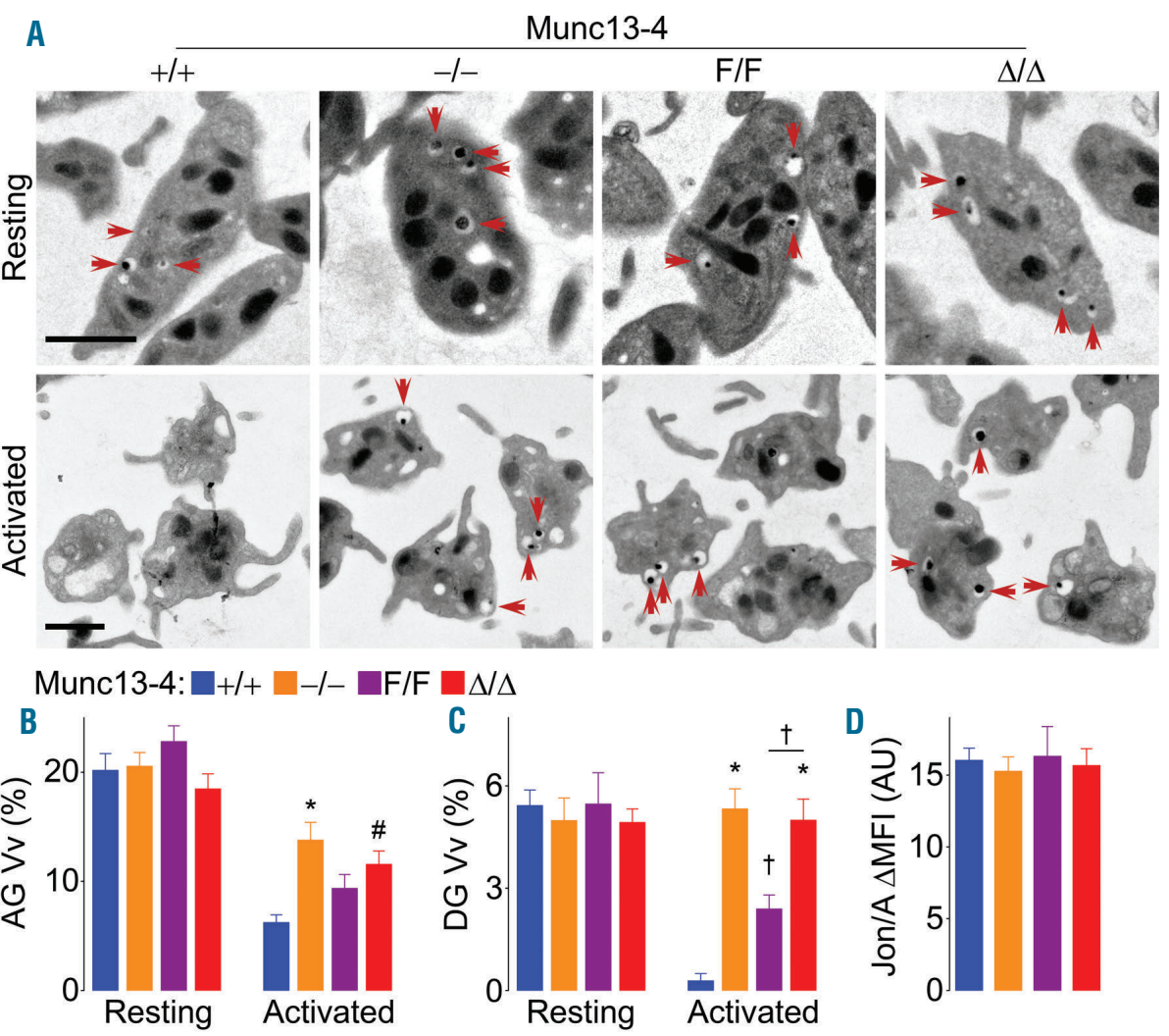

Figure 4. Deletion of Munc13-4 impairs dense granule release. Washed platelets from Munc13-4 mutant mice were activated with thrombin $0.1 \quad \mathrm{U} / \mathrm{mL}$. (A) Representative electron microscopy (EM) cell profiles. Red arrows: dense granules. Scale bar: $1 \mathrm{um}$. Mean volume density (Vv) of alpha granules (AG) (B) and dense granules (DG) (C) obtained by stereology. (D) Mean fluorescence intensity over baseline $(\Delta \mathrm{MFI})$ of Jon/A antibody binding to activated integrin $\alpha_{1 b} \beta_{3}$ on stimulated washed platelets. $\mathrm{N}=5$. Color legend in (B) applies to all panels. Bar: mean; error bar: Standard Error of Mean. $\quad " P<0.05 ; \quad{ }^{\dagger} P<0.01$; $\star P<0.001$; comparisons are with Munc13-4 ${ }^{+/+}$unless otherwise specified.

Table 1. Blood cell counts from Munc13-4 mutant mice.

\begin{tabular}{|c|c|c|c|c|}
\hline & Munc13-4 ${ }^{+/+}$ & Munc13-4- & Munc13-4/F & Munc13-4// \\
\hline Red blood cells $\left(x 10^{12} / \mathrm{L}\right)$ & $8.3 \pm 0.3$ & $9.1 \pm 0.5$ & $8.5 \pm 0.6$ & $8.0 \pm 0.3$ \\
\hline White blood cells $\left(x 10^{9} / \mathrm{L}\right)$ & $2.2 \pm 0.3$ & $2.8 \pm 0.6$ & $3.1 \pm 0.4$ & $2.6 \pm 0.3$ \\
\hline Platelets $\left(\times 10^{9} / \mathrm{L}\right)$ & $613 \pm 28$ & $611 \pm 42$ & $668 \pm 47$ & $645 \pm 50$ \\
\hline
\end{tabular}

Mean \pm Standard Error of Mean. N=7-12.

and D). However, there was a significant decrease in eosinophilic inflammation, which was also independent of Cre expression. Qualitatively, Munc13-4 $4^{\Delta / \Delta}$ and Munc13-4 $4^{--}$mice had reduced histological evidence of tissue eosinophilia (Figure 7E), and quantitatively, a decreased number of eosinophils in BAL fluid (Figure 7F).

\section{Discussion}

\section{Platelet exocytosis}

Exocytosis occurs constitutively in all eukaryotic cells, but some cell types possess a parallel regulated process to release pre-made mediators upon stimulation in a spatiotemporally-controlled manner. All known forms of regulated exocytosis require a Munc13 protein. ${ }^{31,34}$ Platelets and mast cells rely on regulated exocytosis as their main effector mechanism, and both express Munc13-2 and -4 . Like in mast cells, we found that Munc13-4 plays an important role in granule release, but in contrast to mast cells we documented no role for Munc13-2 in platelet exocytosis (Figures 2 and 3). An alternative explanation is that a minor role for Munc13-2 could not be resolved by our methods, which cannot yield the high resolution attained by single-cell membrane capacitance recordings in mast cells. ${ }^{32}$
Previous studies, as well as our current findings in secretion assays and morphometry (Figures 2-4), indicate that Munc13-4 regulates exocytosis of platelet dense granules directly., ${ }^{8,9}$ No ATP release could be detected after Munc13-4 was deleted, and platelets with decreased expression of Munc13-4 released proportionally less ATP than their WT counterparts regardless of the agonist used. By studying the relationship between Munc13-4 expression levels $(0,20,50,100 \%)$ and dense granule release (Figures 2 and 3), we have shown that Munc13-4 is an agonist-independent, rate-limiting factor in dense granule exocytosis. Interestingly, it has been proposed that, besides its known role in priming, Munc13-4 participates in dense granule tethering and conveys $\mathrm{Ca}^{2+}$ sensitivity to platelet exocytosis. ${ }^{7}$ We found no involvement of Munc13-4 in alpha or lysosomal granule exocytosis when we used collagen as agonist. With thrombin, we detected a partial exocytic defect in both types of granules, but only alpha granule release could be rescued by exogenous ADP. This confirms that deletion of Munc13-4 indirectly impairs alpha granule exocytosis, ${ }^{10}$ but that the alpha granule exocytic machinery is intact.

There is evidence that the release of the three types of granules from platelets is differentially regulated, ${ }^{2}$ and it is possible that each requires different exocytic components. 

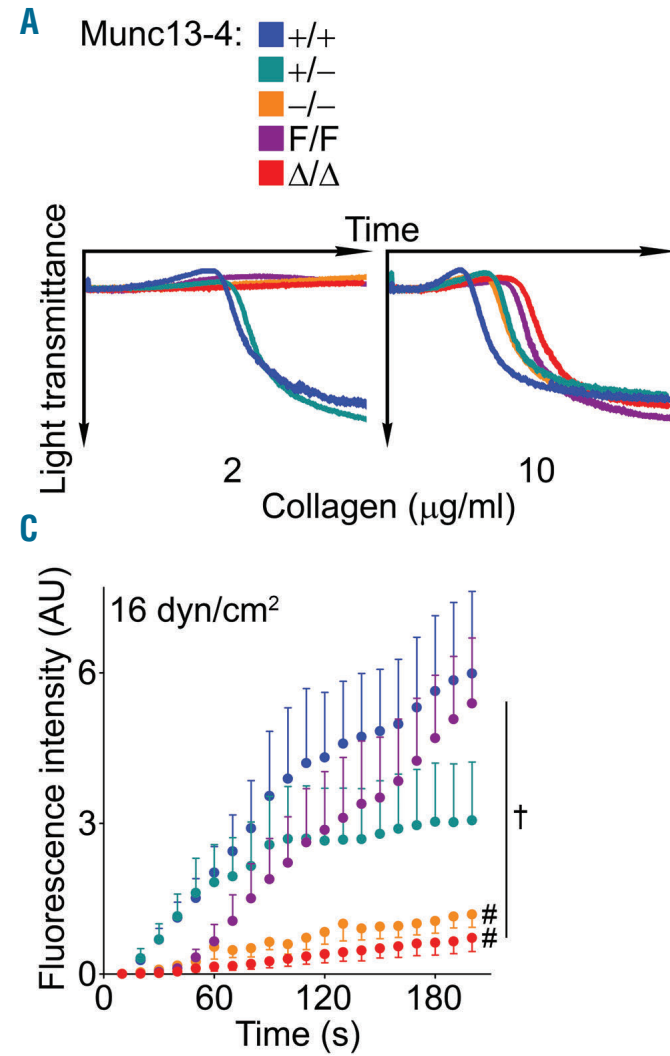

B
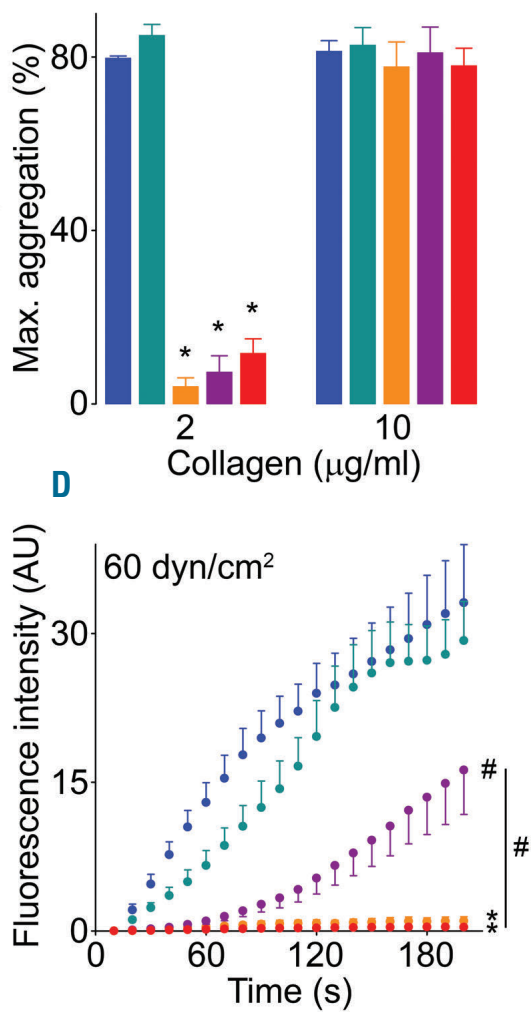

Figure 5. Deletion of Munc13-4 impedes platelet aggregation and interferes with thrombus formation in vitro. Samples from Munc13-4 mutant mice were stimulated with collagen. Representative tracings of platelet aggregation (A) and average maximum aggregation measured by light transmittance (B) on plateletrich plasma. $\mathrm{N}=3-6$. Whole blood was fluorescently-labeled and perfused over collagen-coated plates at low (C) or high (D) sheer stress. Thrombus buildup was monitored by fluorescence intensity and compared at 200 seconds (s). $N=5-10$. Color legend in (A) applies to all panels. Bar or circle: mean; error bar: Standard Error of Mean. ${ }^{\#} P<0.05$; ${ }^{\dagger} P<0.01$; ${ }^{*} P<0.001$; comparisons are with Munc13-4 $4^{+/+}$ unless otherwise specified.
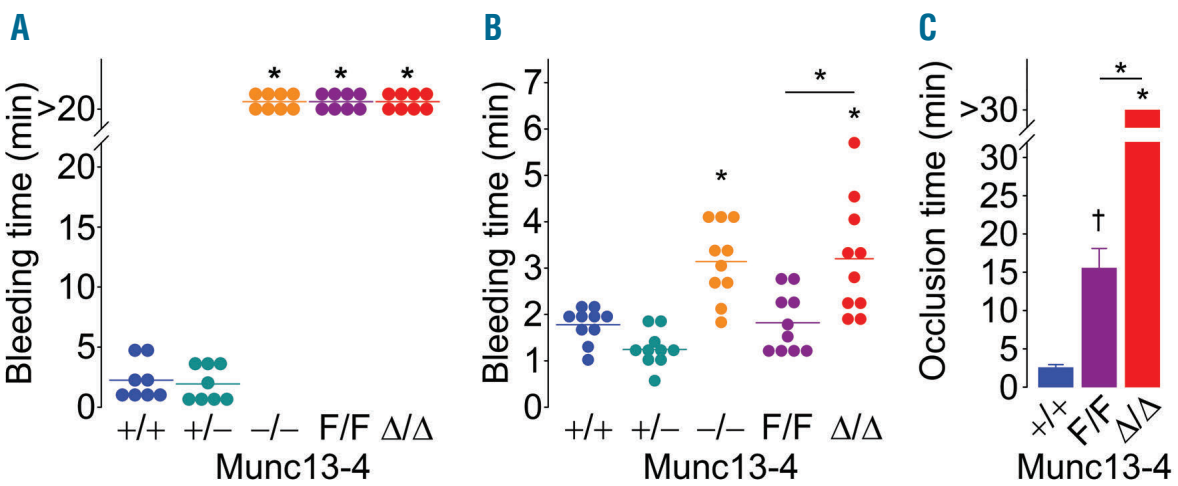

Figure 6. Deletion of Munc13-4 disrupts hemostasis and thrombus formation in vivo. Arterial (A) or venous (B) bleeding was measured in tails from Munc13-4 mutant mice. $\mathrm{N}=8-10$. (C) Time to carotid flow occlusion after applying $\mathrm{FeCl}_{3}$ for 3 minutes (min). $\mathrm{N}=6-9$. Circle: individual mouse; horizontal line or bar: mean; error bar: Standard Error of Mean. ${ }^{\dagger} P<0.01$; ${ }^{\star} P<0.001$; comparisons are with Munc13-4 ${ }^{+/}$unless otherwise specified.

While in mast cells the residual exocytosis observed after removing Munc13-4 was mediated by Munc13-2,32 the priming component that mediates alpha granule exocytosis in platelets remains unknown. Though generally thought of as a neuronal protein, Munc13-1 has been shown to regulate exocytosis in cytotoxic $\mathrm{T}$ lymphocytes, ${ }^{36}$ and it could be involved in platelet alpha granule release. In contrast to Munc13-4, Munc13-1 contains a regulatory diacylglycerol (DAG)-binding C1 domain. ${ }^{37}$ Collagen stimulation of platelets causes more sustained DAG formation than thrombin. ${ }^{38}$ It is possible that Munc13-1 plays a compensatory role in lysosomal granule release, which would explain why we only observed a thrombin-dependent defect in the absence of Munc13-4.

\section{Hemostasis and thrombosis}

Munc13-4 global KO mice have a severe hemostatic defect, and the hypothesis is that this is due to impaired ADP release from platelets. ${ }^{11,13}$ This cannot be tested with a regular global $\mathrm{KO}$ mouse given that Munc13-4 is expressed in other tissues relevant to hemostasis (e.g. endothelium). ${ }^{14}$ Our finding that the bleeding diathesis is identical in global and conditional $\mathrm{KO}$ mice (Figure 6) supports the notion that this Munc13-4-dependent phenome- 
non relies exclusively on platelets. ADP secreted by platelets, acting via $\mathrm{P}_{2} \mathrm{Y}_{1}$ and $\mathrm{P}_{2} \mathrm{Y}_{12}$ receptors on the platelet surface, is known to amplify the primary response provided by collagen or thrombin, and to participate in platelet aggregation, thromboxane A2 generation, and thrombus formation under shear stress. ${ }^{39}$

The release of platelet nucleotides has been found to be critical for in vitro aggregation at lower doses of agonist. ${ }^{9}$
We have shown that platelets unable to release nucleotides (Munc13-4-deficient) fail to aggregate at a low dose of collagen, and that this defect causes the formation of unstable thrombi (Figure 5), which results in disruption of hemostasis and thrombosis (Figure 6). It has been proposed that platelets forming a thrombus can be grouped into two populations: a "core" of contact-dependent highly activated platelets and a "shell" of less activated ADP-

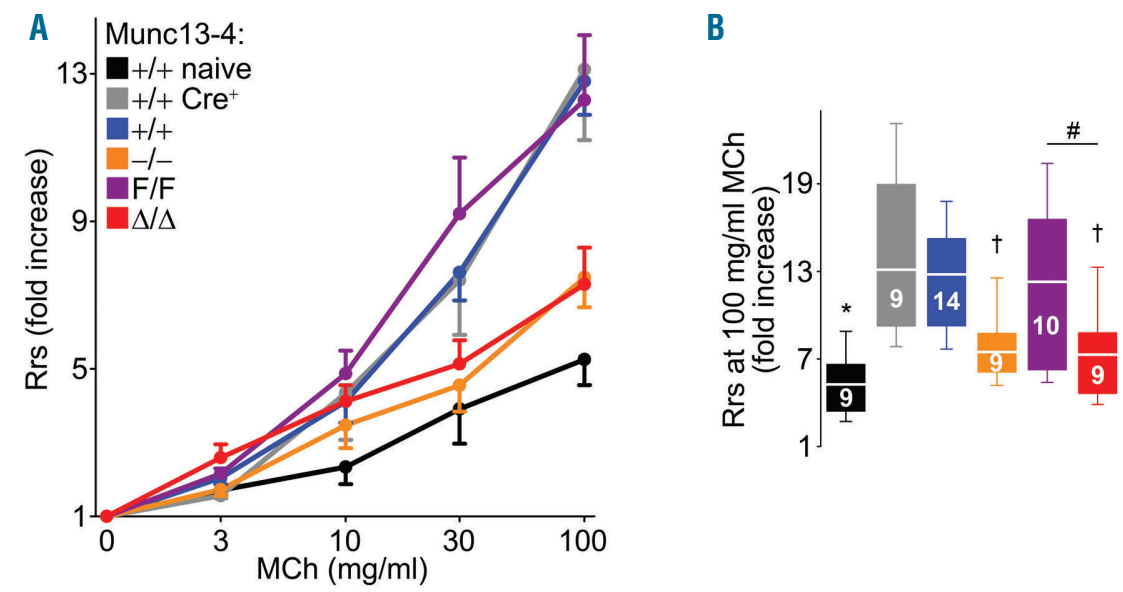

C
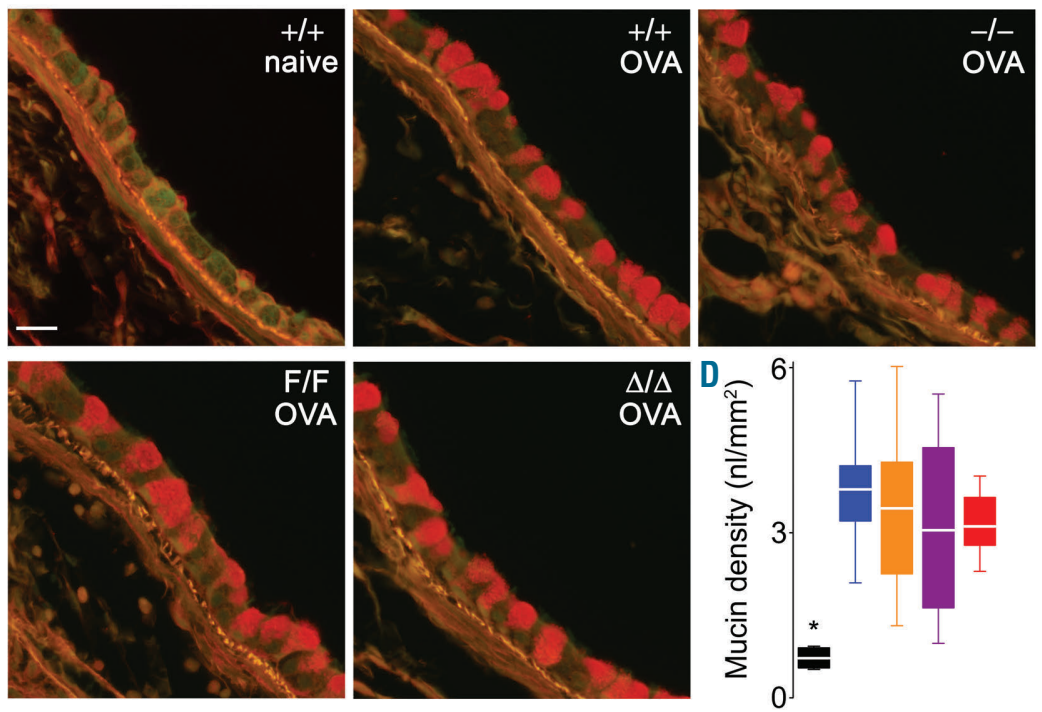

E

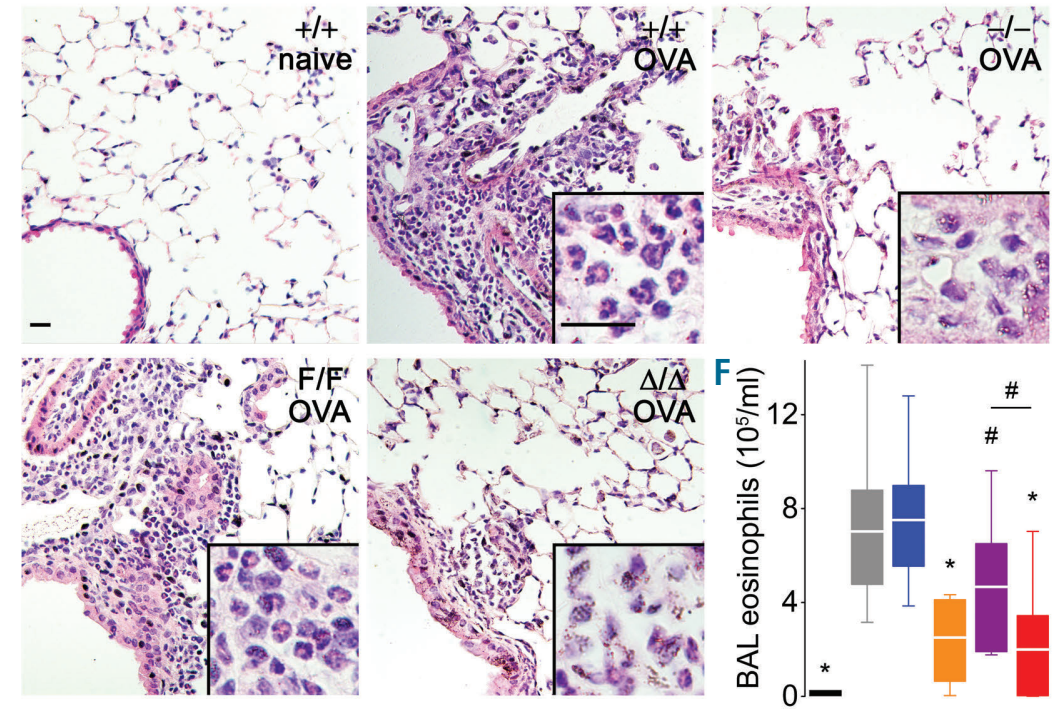

Figure 7. Platelet-specific deletion of Munc13-4 reduces excessive airway constriction to non-specific stimuli (AHR) and lung eosinophilia in a model of asthma. Shown are results from Munc13-4 mutant mice one day after the last airway challenge of an acute allergic airway inflammation model. Naïve: sensitized but not challenged mice. (A) Total respiratory system resistance (Rrs) at increasing doses of nebulized methacholine (Mch). Circle: mean; error bar: Standard Error of Mean. (B) Rrs at the highest dose of Mch. N: number inside boxes. (C) Representative airway sections stained with PAFS (mucin in red). Scale bar: $20 \mathrm{um}$. (D) Mucin volume density at the left lobar bronchus. $\mathrm{N}=9$. (E) Representative lung sections (hematoxylin \& eosin) and identification of eosinophils in tissues (insets). Scale bars $=20 \mu \mathrm{m}$. (F) Eosinophil counts in bronchoalveolar lavage (BAL) fluid. $N=9$. Color legend in (A) applies to all panels. White line: mean; box: $25^{\text {th }}-75^{\text {th }}$ percentile; whiskers: $5^{\text {th }}-95^{\text {th }}$ percentile. $\quad{ }^{*} P<0.05 ; \quad{ }^{\dagger} P<0.01$; ${ }^{*} P<0.001$; comparisons are with sensitized and challenged Munc13-4 ${ }^{+/+}$ unless otherwise specified. 
dependent platelets. ${ }^{40}$ Therefore, partial defects in ADP release would be expected to translate into thrombi that weaken and break as shear stress increases, and this is exactly what we observed in a perfusion chamber in hypomorphic Munc13-4 $4^{\mathrm{F} / \mathrm{F}}$ platelets (Figure 5). Moreover, we obtained a strong hemostatic defect in Munc13-4 ${ }^{\mathrm{F} / \mathrm{F}}$ mice when we transected the tail artery, but no prolonged bleeding time when we sectioned only the tail dorsal vein (Figure 6). Taken together, these results show that by controlling platelet dense granule release, Munc13-4-dependent exocytosis is a limiting factor for platelet aggregation, thrombus stabilization and hemostasis.

\section{Allergic airway inflammation}

Asthma is a chronic airway disease characterized by excessive airway constriction to non-specific stimuli (also known as AHR), airway eosinophilic inflammation, and epithelial mucous metaplasia. ${ }^{41}$ Although hyperproduction of mucins and secretion of mucus by airway epithelial cells have been shown to be a component of AHR, ${ }^{42}$ we found that platelet exocytosis mediated by Munc13-4 did not influence airway mucous metaplasia. Instead, the decrease in AHR in animals with platelets deficient in Munc13-4 correlated with a reduction in the number of eosinophils recruited to the airways (Figure 6).

Platelets store in their alpha and dense granules many mediators and membrane-bound proteins linked to allergic airway inflammation. Platelet $P$-selectin mediates the recruitment of eosinophils and lymphocytes into the airways of mice subjected to a model of asthma, ${ }^{43}$ and recent evidence suggests a similar function in humans. ${ }^{44,45}$ Additionally, exocytosis of alpha granule contents may influence inflammation through many chemokines; for example, PF4 can induce AHR in rats. ${ }^{46}$

Platelets actively take up serotonin from plasma and concentrate it in their dense granules, becoming the main source of serotonin outside the central nervous system. ${ }^{47}$ Serotonin modulates adhesion, migration, and cytokine and chemokine production in inflammatory cells and lung epithelial cells. ${ }^{48}$ Serotonin also induces bronchoconstriction, and mice unable to synthesize serotonin in peripheral tissues had a marked decrease in platelet serotonin and AHR. ${ }^{26} \mathrm{ADP}$ can induce changes on the endothelium that result in leukocyte transendothelial migration via the $\mathrm{P} 2 \mathrm{Y}_{1}$ and $\mathrm{P} 2 \mathrm{Y}_{2}$ receptors, ${ }^{49,50}$ and global deletion of the ADP receptor $\mathrm{P}_{2} \mathrm{Y}_{12}$ in mice has been shown to partially protect from asthma. ${ }^{27}$ Even though treatment with the P2Y inhibitor clopidogrel had contradictory outcomes in mouse models of asthma, ${ }^{27-29}$ it is currently being tested in asthmatic patients (clinicaltrials.gov identifier: 01955512). On the other hand, the PRINA trial failed to show a significant decrease in mannitol-induced AHR in patients with asthma treated with prasugrel. ${ }^{51}$ The mechanism of action of anti-P2 $\mathrm{Y}_{12}$ thienopyridines in allergic inflammation needs to be clarified, because it may be acting on eosinophils and not necessarily on platelets. ${ }^{28}$ Other molecules present in dense granules such as ATP, ${ }^{52}$ glutamate $^{53}$ and polyphosphates ${ }^{54}$ can influence different steps of the allergic inflammatory response. Therefore, the lack of Munc13-4 in platelets could significantly affect the development of asthma by directly impeding dense granule exocytosis and indirectly hindering alpha granule release.

Up until now all the evidence supporting a role for platelets in asthma has come from in vitro studies, ${ }^{55}$ in vivo experimentation on platelet-depleted animals ${ }^{24,25,56}$ or global $\mathrm{KO}$ mice, ${ }^{23,26,27,43}$ and from pharmacological studies that targeted receptors expressed in multiple cell types ${ }^{28-30}$ Here we show in mice with normal numbers of circulating platelets that selective deletion of Munc13-4 in platelets results in reduced AHR and lung eosinophilia, most likely because of impaired dense granule release.

It has been proposed that platelet activation could lead to either a hemostatic or an inflammatory response independently of each other. ${ }^{18}$ A recent publication suggests that low concentrations of collagen are capable of inducing platelet secretion of soluble factors, without causing aggregation or any of the other characteristic features of platelet activation. ${ }^{35}$ Studies on mouse models of allergic and bacterial airway inflammation suggest that platelet $\mathrm{P}_{12} \mathrm{Y}_{12}$ participates mostly in hemostasis, $\mathrm{P}_{2 \mathrm{Y}_{14}}$ in inflammation, and $\mathrm{P} 2 \mathrm{Y}_{1}$ in both. ${ }^{29,30}$ The ligand of $\mathrm{P} 2 \mathrm{Y}_{1}$ (ADP) is stored in platelet dense granules, but it is unclear whether the ligand for P2Y ${ }_{14}$ (UDP-glucose) comes from platelets ${ }^{57}$ or from other cells. ${ }^{58}$ Hence, the defect in dense granule exocytosis we noted in platelets lacking Munc13-4 could result in failure to activate $\mathrm{P} 2 \mathrm{Y}_{1}, \mathrm{P}_{2} \mathrm{Y}_{12}$ and perhaps $\mathrm{P} 2 \mathrm{Y}_{14}$. The simultaneous failure to activate all these receptors could explain why our mutant animals have both abnormal hemostasis and decreased allergic airway inflammation.

\section{Acknowledgments}

The authors would like to thank Margaret M. Gondo (University of Houston) for her assistance with the electron microscopy, Kimberly Langlois and Ngoc-Anh Bui-Thanh (Baylor College of Medicine) for their assistance with the in vivo thrombosis assay, and Terry Hoppe (Texas A\&M Institute of Biosciences and Technology) for his assistance manufacturing the tail-bleeding device.

\section{Funding}

This project was supported by the National Institutes of Health AI093533A, CA016672 and HL116524, and the Department of Veterans Affairs Merit Review Award 101 BX002551. EIC received support from Instituto Tecnológico y de Estudios Superiores de Monterrey and Consejo Nacional de Ciencia y Tecnologia (CONACyT, PhD grant scholarship \# 352566). The contents of this manuscript do not represent the views of the Department of Veterans Affairs or the United States Government.

\section{References}

1. Blair P, Flaumenhaft R. Platelet alpha-granules: basic biology and clinical correlates. Blood Rev. 2009;23(4):177-189.

2. Jonnalagadda D, Izu LT, Whiteheart SW. Platelet secretion is kinetically heterogeneous in an agonist-responsive manner.
Blood. 2012;120(26):5209-5216.

3. Ciferri S, Emiliani C, Guglielmini G, Orlacchio A, Nenci GG, Gresele P. Platelets release their lysosomal content in vivo in humans upon activation. Thromb Haemost. 2000;83(1):157-164.

4. Chen YA, Scheller RH. SNARE-mediated membrane fusion. Nat Rev Mol Cell Biol. 2001;2(2):98-106.
5. Klenchin VA, Martin TF. Priming in exocytosis: attaining fusion-competence after vesicle docking. Biochimie. 2000;82(5):399-407.

6. Ma C, Li W, Xu Y, Rizo J. Munc13 mediates the transition from the closed syntaxinMunc18 complex to the SNARE complex. Nat Struct Mol Biol. 2011;18(5):542-549.

7. Chicka MC, Ren Q, Richards D, et al. Role of Munc13-4 as a Ca2+-dependent tether 
during platelet secretion. Biochem J. 2016; 473(5):627-639.

8. Schumacher D, Strilic B, Sivaraj KK, Wettschureck N, Offermanns S. Plateletderived nucleotides promote tumor-cell transendothelial migration and metastasis via P2Y2 receptor. Cancer Cell. 2013;24(1):130-137.

9. Ren $\mathrm{Q}$, Wimmer C, Chicka MC, et al. Munc13-4 is a limiting factor in the pathway required for platelet granule release and hemostasis. Blood. 2010;116(6):869-877.

10. Harper MT, van den Bosch MT, Hers I, Poole AW. Platelet dense granule secretion defects may obscure alpha-granule secretion mechanisms: evidence from Munc13-4-deficient platelets. Blood. 2015; 125(19):30343036.

11. Savage JS, Williams CM, Konopatskaya O, Hers I, Harper MT, Poole AW. Munc13-4 is critical for thrombosis through regulating release of ADP from platelets. J Thromb Haemost. 2013;11(4):771-775.

12. Schumacher D, Strilic B, Sivaraj KK, Wettschureck N, Offermanns S. Response to Harper et al. Cancer Cell. 2013; 24(3):288.

13. Stegner D, Deppermann C, Kraft P, et al. Munc13-4-mediated secretion is essential for infarct progression but not intracranial hemostasis in acute stroke. J Thromb Haemost. 2013;11(7):1430-1433.

14. Chehab T, Santos NC, Holthenrich A, et al. A novel Munc13-4/S100A10/annexin A2 complex promotes Weibel-Palade body exocytosis in endothelial cells. Mol Biol Cell. 2017;28(12):1688-1700.

15. Feldmann J, Callebaut I, Raposo G, et al Munc13-4 is essential for cytolytic granules fusion and is mutated in a form of familial hemophagocytic lymphohistiocytosis (FHL3). Cell. 2003;115(4):461-473.

16. Nakamura L, Bertling A, Brodde MF, et al. First characterization of platelet secretion defect in patients with familial hemophagocytic lymphohistiocytosis type 3 (FHL-3). Blood. 2015;125(2):412-414.

17. Chen Y, Wang Z, Cheng Y, Tang Y. Novel mutations in the UNC13D gene carried by a Chinese neonate with hemophagocytic lymphohistiocytosis. Yonsei Med J. 2013; 54(4):1053-1057.

18. Idzko M, Pitchford S, Page C. Role of platelets in allergic airway inflammation. J Allergy Clin Immunol. 2015;135(6):14161423.

19. Sullivan PJ, Jafar ZH, Harbinson PL, Restrick LJ, Costello JF, Page CP. Platelet dynamics following allergen challenge in allergic asthmatics. Respiration. 2000; 67(5):514-517.

20. Kowal K, Pampuch A, Kowal-Bielecka O, DuBuske LM, Bodzenta-Lukaszyk A. Platelet activation in allergic asthma patients during allergen challenge with Dermatophagoides pteronyssinus. Clin Exp Allergy. 2006;36(4):426-432.

21. Jeffery PK, Wardlaw AJ, Nelson FC, Collins $\mathrm{JV}$, Kay AB. Bronchial biopsies in asthma. An ultrastructural, quantitative study and correlation with hyperreactivity. Am Rev Respir Dis. 1989;140(6):1745-1753.

22. Metzger WJ, Sjoerdsma K, Richerson HB, et al. Platelets in bronchoalveolar lavage from asthmatic patients and allergic rabbits with allergen-induced late phase responses. Agents Actions Suppl. 1987;21:151-159.

23. Pitchford SC, Momi S, Baglioni S, et al. Allergen induces the migration of platelets to lung tissue in allergic asthma. Am J Resp Crit Care. 2008;177(6):604-612.

24. Pitchford SC, Yano H, Lever R, et al. Platelets are essential for leukocyte recruitment in allergic inflammation. J Allergy Clin
Immunol. 2003;112(1):109-118.

25. Coyle AJ, Page CP, Atkinson L, Flanagan R, Metzger WJ. The requirement for platelets in allergen-induced late asthmatic airway obstruction. Eosinophil infiltration and heightened airway responsiveness in allergic rabbits. Am Rev Respir Dis 1990;142(3):587-593.

26. Durk T, Duerschmied D, Muller T, et al. Production of serotonin by tryptophan hydroxylase 1 and release via platelets contribute to allergic airway inflammation. Am J Resp Crit Care. 2013;187(5):476-485.

27. Paruchuri S, Tashimo H, Feng C, et al. Leukotriene E4-induced pulmonary inflammation is mediated by the P2Y12 receptor. J Exp Med. 2009;206(11):2543-2555.

28. Suh DH, Trinh HK, Liu JN, et al. P2Y12 antagonist attenuates eosinophilic inflammation and airway hyperresponsiveness in a mouse model of asthma. J Cell Mol Med. 2016;20(2):333-341

29. Amison RT, Momi S, Morris A, et al. RhoA signaling through platelet $\mathrm{P} 2 \mathrm{Y}(1)$ receptor controls leukocyte recruitment in allergic mice. I Allergy Clin Immunol. 2015;135(2):528-538.

30. Amison RT, Arnold S, O'Shaughnessy BG, et al. Lipopolysaccharide (LPS) induced pulmonary neutrophil recruitment and platelet activation is mediated via the P2Y1 and P2Y14 receptors in mice. Pulm Pharmacol Ther. 2017;45:62-68.

31. Varoqueaux F, Sigler A, Rhee JS, et al. Total arrest of spontaneous and evoked synaptic transmission but normal synaptogenesis in the absence of Munc13-mediated vesicle priming. Proc Natl Acad Sci USA. 2002, 99(13):9037-9042

32. Rodarte EM, Ramos MA, Davalos AJ, et al. Munc13 proteins control regulated exocytosis in mast cells. J Biol Chem. 2018, 293(1):345-358.

33. Schwenk F, Baron U, Rajewsky K. A cretransgenic mouse strain for the ubiquitous deletion of loxP-flanked gene segments including deletion in germ cells. Nucleic Acids Res. 1995;23(24):5080-5081.

34. Augustin I, Rosenmund C, Sudhof TC, Brose N. Munc13-1 is essential for fusion competence of glutamatergic synaptic vesicles. Nature. 1999;400(6743):457-461

35. Ollivier V, Syvannarath V, Gros A, et al. Collagen can selectively trigger a platelet secretory phenotype via glycoprotein VI. PLoS One. 2014;9(8):e104712.

36. Dudenhoffer-Pfeifer M, Schirra C, Pattu V, et al. Different Munc13 isoforms function as priming factors in lytic granule release from murine cytotoxic T lymphocytes. Traffic. 2013;14(7):798-809.

37. Koch H, Hofmann K, Brose N. Definition of Munc13-homology-domains and characterization of a novel ubiquitously expressed Munc13 isoform. Biochem J. 2000;349(Pt 1):247-253

38. Werner MH, Hannun YA. Delayed accumulation of diacylglycerol in platelets as a mechanism for regulation of onset of aggregation and secretion. Blood. 1991; 78(2):435444.

39. Li Z, Delaney MK, O'Brien KA, Du X Signaling during platelet adhesion and activation. Arterioscler Thromb Vasc Biol. 2010;30(12):2341-2349.

40. Stalker TJ, Traxler EA, Wu J, et al Hierarchical organization in the hemostatic response and its relationship to the plateletsignaling network. Blood. 2013; 121(10):1875-1885.

41. Broide DH. Molecular and cellular mechanisms of allergic disease. J Allergy Clin
Immunol. 2001;108(2 Suppl):S65-71

42. Evans CM, Raclawska DS, Ttofali F, et al. The polymeric mucin Muc5ac is required for allergic airway hyperreactivity. Nat Commun. 2015;6:6281

43. Pitchford SC, Momi S, Giannini S, et al. Platelet $\mathrm{P}$-selectin is required for pulmonary eosinophil and lymphocyte recruitment in a murine model of allergic inflammation. Blood. 2005;105(5):2074-2081.

44. Johansson MW, Mosher DF. Activation of beta1 integrins on blood eosinophils by Pselectin. Am J Resp Cell Mol. 2011; 45(4):889-897.

45. Johansson MW, Han ST, Gunderson KA, Busse WW, Jarjour NN, Mosher DF. Platelet activation, P-selectin, and eosinophil beta1integrin activation in asthma. Am J Resp Crit Care. 2012;185(5):498-507.

46. Coyle AJ, Uchida D, Ackerman SJ, Mitzner W, Irvin CG. Role of cationic proteins in the airway. Hyperresponsiveness due to airway inflammation. Am J Resp Crit Care. 1994:150(5 Pt 2):S63-71.

47. Mercado CP, Kilic F. Molecular mechanisms of SERT in platelets: regulation of plasma serotonin levels. Mol Interv. 2010; 10(4):231241.

48. Bayer $\mathrm{H}$, Muller $\mathrm{T}$, Myrtek $\mathrm{D}$, et al Serotoninergic receptors on human airway epithelial cells. Am J Resp Cell Mol. 2007; 36(1):85-93

49. Kukulski F, Ben Yebdri F, Bahrami F, Fausther M, Tremblay A, Sevigny J. Endothelial P2Y2 receptor regulates LPS-induced neutrophil transendothelial migration in vitro. Mol Immunol. 2010;47(5):991-999.

50. Shen J, DiCorleto PE. ADP stimulates human endothelial cell migration via P2Y1 nucleotide receptor-mediated mitogen-activated protein kinase pathways. Circ Res. 2008;102(4):448-456.

51. Lussana F, Di Marco F, Terraneo S, et al Effect of prasugrel in patients with asthma: results of PRINA, a randomized, doubleblind, placebo-controlled, cross-over study. J Thromb Haemost. 2015;13(1):136-141.

52. Younas M, Hue S, Lacabaratz C, et al. IL-7 modulates in vitro and in vivo human memory $\mathrm{T}$ regulatory cell functions through the CD39/ATP axis. I Immunol. 2013;191(6):3161-3168

53. Ganor Y, Besser M, Ben-Zakay N, Unger T, Levite M. Human T cells express a functional ionotropic glutamate receptor GluR3, and glutamate by itself triggers integrin-mediated adhesion to laminin and fibronectin and chemotactic migration. J Immunol. 2003;170(8):4362-4372

54. Dinarvand P, Hassanian SM, Qureshi SH, et al. Polyphosphate amplifies proinflammatory responses of nuclear proteins through interaction with receptor for advanced glycation end products and P2Y1 purinergic receptor. Blood. 2014:123(6):935-945

55. Palma-Carlos AG, Palma-Carlos ML, Santos MC, de Sousa JR. Platelet aggregation in allergic reactions. Int Arch Aller a Imm. 1991;94(1-4):251-253

56. Pitchford SC, Riffo-Vasquez Y, Sousa A, et al. Platelets are necessary for airway wall remodeling in a murine model of chronic allergic inflammation. Blood. 2004, 103(2):639-647.

57. Wandall HH, Rumjantseva V, Sorensen AL, et al. The origin and function of platelet glycosyltransferases. Blood. 2012; 120(3):626635.

58. Kreda SM, Okada SF, van Heusden CA, et al. Coordinated release of nucleotides and mucin from human airway epithelial Calu-3 cells. J Physiol. 2007;584(Pt 1):245-259. 